\title{
Health Behavior Patterns Among First-Year and Non-First-Year College Students Attending a North Carolina Historically Black University
}

\author{
Dixie Dennis and Terence Hicks
}

The major purpose of this study was to conduct a baseline investigation of self-rated health behavior and quality of life among first-year and non-first-year college students. The authors used a quality of life questionnaire that was designed to gauge college students' health status, lifestyle, mental health, and living conditions. Results from this study indicated that there were significant differences among health behavior patterns between first-year and non-first-year college students. Most importantly, this study provides compelling information regarding the physical and psychological health behaviors among a mostly African American student population who attended a historically Black university in North Carolina. Implications for university student personnel, counselors, and faculty are discussed.

Note: This study was supported by Grant Number P20 MD001089 from the National Center of Minority Health and Health Disparities, National Institutes of Health. Its contents are solely the responsibility of the authors and do not necessarily represent the official views of National Institutes of Health.

One of the primary goals of Healthy People 2010 (U.S. Department of Health and Human Services [USDHHS], 2000) is to increase the quality of life for Americans, including college-aged Americans. Likewise, university educators have placed a great emphasis on college students' health-related quality of life because these students typically experience behavioral-associated threats to health that are unique to this phase in their lives (Grace, 1997). Lau, Quadrel, and Hartman (1990) reported that there were substantial negative behavior changes during the first three years of college. For most college students, not only do "college-appropriate" behavior patterns (e.g., unhealthy eating and sleeping behaviors) typically become predictors of overall health in adulthood (Sparling \& Snow, 2002; Taylor, 1999), they frequently prelude less healthy, and often stressful, behaviors such as smoking (Naquin \& Gilbert, 1996) and drinking (Morgan, 1997; McCormack, 1996) during the college years. Regarding psychological stressors, in a 2001 study conducted by UCLA's Higher Education Research Institute (2002), most college students reported being most stressed over financial hardships.

Specific to college students attending historically Black universities, Ford and Goode

\footnotetext{
Dixie Dennis (dennisdi@apsu.edu) is a professor and chair for the Department of Health \& Human Performance at Austin Peay State University. Terence Hicks (thicks@uncfsu.edu) is an associate professor of Research in the Educational Leadership Doctoral Program and director of the Research Center at Fayetteville State University in North Carolina.
} 
(1994) surveyed the health behaviors of 224 undergraduate students enrolled in health education classes. Among these students, the rate of cigarette smoking was low (4\%), with more men than women reporting this behavior. More recently, however, Powe and Finnie (2005) reported that among African American college students attending a historically Black university, approximately $18 \%$ currently smoke.

In their 1994 study, Ford and Goode revealed that $63 \%$ of the students whom they surveyed consumed alcohol, with more women than men reporting drinking. Also, more than half (55.4\%) of the students surveyed reported that they were not involved in daily physical activity. Overall, students reported that they believed the most important health issues facing college students at that time included HIV/AIDS and other sexually transmitted diseases, birth control, date rape, stress management, suicide, and alcohol and other drugs. Ford and Goode concluded there was "a need for more baseline data to identify the health behaviors of minority populations, particularly first- and second-year African American college students" (p. 209).

The purpose of this study was to conduct a baseline investigation of self-rated physical and psychological behaviors among first-year and non-first-year (sophomore, junior, senior, graduate) college students, most of whom were African American. The authors used a quality of life questionnaire that gauged the college student's health status, lifestyle, mental health, and living conditions. The significance of this study could offer a baseline of follow up in identifying certain subgroups of students who are at particular risk for certain types of depression, stress, health behaviors, mental health and health habits while attending college.

\section{Method}

\section{Instrument}

The 30-item questionnaire used is this study was the Health Behaviors, Self-Rated Health and Quality of Life (Vaez \& Laflamme, 2003), also known as the Quality of Life (QOL) survey. For this study, a demographic section, which included questions related to age, sex, race, and living conditions, was added to the QOL questionnaire. In addition to the questionnaire's demographic section, the original QOL sections include Life-Style, Student Life Stressors, and Health Status.

Examples of health behavior variables assessed on the questionnaire included the frequency of alcohol consumed (never, once a month, 2-4 times a month, 2-3 times a week, 4 times a week or more) and, if they consumed, the typical amount of alcohol consumed on each occasion (1-2 glasses, 3-4 glasses, 5-6 glasses, 7-9 glasses, 10 glasses or more). To answer questions about cigarettes smoked, participants' response alternatives were "yes, daily," "yes, sometimes," or "no." Physical activity was assessed with a single question concerning the frequency of exercise on a 5-point scale (never, once a month, 2-4 times a month, 2-3 times a week, or 4 times a week or more). To answer questions related to life stressors over the preceding academic year, students chose between responses based on a 4-point scale (not at all stressed, slightly stressed, 
rather stressed, highly stressed). To answer questions related to perceived health status and quality of life, students rated their physical, psychological, and overall health, respectively, on a 5-point scale (very good, good, neither good nor poor, poor, very poor). As a measure of psychological or psychosomatic problems, students responded to a 4-point scale (not at all, a little, quite a lot, or a lot). Three questions were "ladder questions." A ladder question typically is introduced the following way: "Here is a picture of a ladder. At the bottom of the ladder, 1 is the worst life you might reasonably expect to have, and 10, at the top, is the best life you might reasonably expect to have. Indicate where on the ladder your life is right now." According to Vaez and Laflamme (2003), this "ladder scale" is a widely recognized measure that has shown high validity.

\section{Procedures}

Students who were enrolled in spring 2005 courses at a 4-year public research and doctoral-granting historically Black North Carolina university completed the QOL. Upper and lower level courses from each discipline across campus were randomly selected after the university's spring 2005 course schedule was reviewed. After obtaining permission from the university Institutional Review Board (IRB), professors of the randomly-selected courses were contacted for an agreeable time to administer the survey. Before completing the survey, students signed an informed consent form. All but one student volunteered to complete the questionnaire. Each QOL answer sheet was assigned a number and entered into the Statistical Package for the Social Sciences (SPSS). Completed data sheets and signed consent forms were kept in separate locked cabinets.

\section{Statistical Analysis}

The data were analyzed question by question to determine the number and percent of responses for each choice by first-year and non-first-year student status. A chi-square test was conducted on all data using SPSS. All comparisons were made assuming an alpha $=0.05$ significance level.

\section{Results}

The majority of the 514 participants $(71 \%)$ were college students between the ages of 18 and 23 years old and mostly African American (77\%). Sixty-eight percent of the sample was female. Specific to university classification, there were freshmen $(53 \%)$, sophomores (15\%), juniors (13\%), seniors (6\%), and graduate students (13\%).

Regarding the entire sample of first-year and non-first-year students, similarities existed for using alcohol, tobacco, and other drugs (ATOD), with males consistently reporting engaging more in these behaviors than females. Approximately $70 \%$ of first-year and $78 \%$ of non-first-year students reported drinking alcohol. Only about $1 \%$ of all students, first-year and non-first-year, reported drinking alcohol four or more times a week. Of those students who reported drinking, 6.6\% (first-year and non-first- 
year students) reported drinking three to four drinks on each occasion, and an average of about $4.5 \%$ of both groups reported engaging in "binge drinking" (at least five drinks per occasion).

Only about $4 \%$ of all students reported smoking on a daily basis, with $45 \%(n=230)$ first-year and 40.2\% $(n=204)$ non-first-year students reporting not smoking at all. Only 9 first-year and 7 non-first-year students reported using illegal drugs on a daily basis. Among all students, illegal drug use (daily and sometimes) was $6.05 \%$, with $45.6 \%$ of first-year and $42.3 \%$ of non-first-year reporting never using illegal drugs. Among all ATOD use, males reported more activity than females. Regarding exercise, almost 10\% of both first-year and non-first-year students reported never exercising. Most students, first-year and non-first-year (15.8\% and $16.4 \%$ respectively), reported exercising two to three times a week.

In the Life-Style section of the questionnaire, the question "How often do you drink alcohol?" revealed a significant difference between first-year and non-first-year college students. While $30.1 \%(n=154)$ of first-year college students reported that they never drink alcohol, $21.5 \%(\mathrm{n}=110)$ of non-first-year college students indicated that they never consumed alcohol in the preceding academic year $\left(\chi^{2}(5)=20.327, p<.001\right)$.

One question in the Student Life Stressors section showed significant differences between first-year and non-first-year students. A significant difference was found regarding the perceived potential source of stressors for the preceding academic year. More first-year college students (18.1\%) indicated that they were not at all stressed due to poor finances as opposed to $11.4 \%$ of non-first-year college students $\left(\chi^{2}(4)=10.674\right.$, $\mathrm{p}<.05)$.

In the Health Status section, significant differences were found between first-year and non-first-year college students on four questions related to listed psychological or psychosomatic problem (e.g., irritation, anxiety, depression, tiredness, upset stomach). Significantly more first-year college students $(28.2 \%)$ reported that they did not experience any anxiety during the preceding academic year than non-first-year college students $(15.4 \%)\left(\chi^{2}(3)=22.577, \mathrm{p}<.001\right)$.

Also, a significant difference was found between first-year students and non-firstyear students regarding the respondents' lives being restricted due to temporary disease (less than one month) and chronic disease (more than one month, injury, or functional handicap), with more first-year college students (45.4\%) reporting that they did not experience any physical difficulties that restricted their life than non-first-year college students $(34.6 \%)\left(\chi^{2}(4)=14.120, \mathrm{p}<.001\right)$.

Regarding the question about seeking health care due to physical or psychological problems, a significantly larger percentage of first-year college students $(39.3 \%)$ indicated that they did not seek health care due to physical or psychological problems during the academic year as opposed to non-first-year college students (29.9\%) $\left(\chi^{2}(2)=7.996, p<.05\right)$. When answering the question "How would you rate the overall health status of college students?", significantly more first-year college students (19.7\%) than non-first-year college students (12.2\%) reported that the overall health status of college students was "bad" as opposed to non-first-year college students 
$\left(\chi^{2}(10)=18.720, \mathrm{p}<.05\right)$.

\section{Discussion}

Students in this study from a historically Black university reported more alcohol use (70\% first-year and $78.5 \%$ non-first-year) than what was reported by students from eight historically Black universities (63\%) in Ford and Goode's (1994) study. While this finding may indicate that these college students drink more than the students in Ford and Goode's study 10 years ago, it is noteworthy that more first-year students $(30.1 \%)$ in the current study indicated that they never drank alcohol as opposed to the non-first-year students $(21.5 \%)$. What is not apparent, however, is whether drinking more is a normal progression behavior among college students or whether this difference is an isolated event.

Even though Lau, Quadrel, and Hartman (1990) reported that substantial negative behaviors existed during the first three years of college, they did not indicate whether these negative behaviors, including drinking alcohol, were progressive in nature or whether more people began engaging in negative behaviors during their progression through college. Obviously, less drinking attributed to the legal drinking age being raised to 21 (O'Malley \& Wagenaar, 1991) has not persisted into the 21st century, at least not for this primarily African American student population. Of particular concern for today's African American college students is that there are disproportionately more problems associated with heavy drinking among African Americans than other populations (Obot, 1996).

Similar to what Ford and Goode (1994) found, only about 4\% of students in this study - first-year and non-first-year-engaged in smoking cigarettes daily. This low percentage may be even more in line when considering that African American students typically smoke less than other students (USDHHS, 2000). In contrast to this study's findings and the findings in the Ford and Goode study on the low percentage of African American students who smoke cigarettes, Powe and Finnie (2005) found that as many as $18 \%$ of African American college students smoke.

On average, only $6.05 \%$ of the total student sample in this study reported using illegal drugs ("daily" and "sometimes" combined). This percentage is lower than the U.S. Department of Health and Human Services (1999) which reported that an average of $16.1 \%$ college students aged 18-25 engaged in illicit drug use. As with tobacco and alcohol use, however, the lower percentage for students in this study may be due to African Americans engaging in illicit drugs less than other populations (USDHHS, 2000). Clearly, other research has indicated that alcohol and drug consumption among African American college students is an example of a problem to be studied and addressed in a campus health promotions and drug and alcohol prevention center.

The low average percentage $(9.2 \%)$ of both first-year and non-first-year students reporting that they never exercise, coupled with only approximately $16 \%$ of students in this study who exercise 2-3 times a week, is lower than the national average of $20 \%$ of males and females with some college experience who engage in moderate physical 
activity as reported in Healthy People 2010 (USDHHS, 2000). Both of these percentages are lower than the percentage of students (55.4\%) in Ford and Goode's (1994) study which reported not being involved in daily physical activity.

In a time in America when there are more overweight and obese people than ever before (USDHHS, 2000), it seems particularly important for health educators to encourage African American students to engage in more exercise. In a similar study conducted by Hicks and Miller (in press), a larger percentage of female participants $(15.6 \%)$ reported that they did not participate in any physical activities over the academic year as opposed to the male college students $(2.8 \%)$. The physical inactivity patterns of first-year and non-first-year African American college students merit attention.

According to Hicks and Miller's study, this is an indication that more wellness programs that encourage physical exercise and relaxation are needed in the academic setting. There is clear evidence that physical activity at least three times a week is associated with better health outcomes and lowers the risk of some cancers and cardiovascular disease (Lewis et al., 1993).

While many similarities exist between first-year and non-first-year students, significant differences also exist. For example, significantly more first-year students reported that they were not stressed due to poor finances than non-first-year students ( $18.1 \%$ and $11.4 \%$ respectively). One possible reason for this difference is that first-year students may be on scholarships and/or receiving financial aid in greater numbers than non-first-year students and, therefore, are not as stressed about finances. Regardless, both groups of students in this study report being less worried about financial hardships than those 12 years ago when Ford and Goode (1994) revealed that "most" college students reported being stressed over financial hardships. Again, the answer may reside in more scholarships and financial aid awarded today to this mostly African American sample than in earlier times.

Relative to psychological or psychosomatic problems, significantly more first-year students in this study reported not experiencing anxiety compared to non-first-yearstudents. Perhaps problems related to college life naturally increase as students progress through their college years. Also, it is possible that students may have more difficulty to managing problems, in general, as the college years progress. Possibly related to this finding is that fewer first-year students than non-first-year students reported experiencing restrictions due to temporary and chronic diseases. Naturally, then, fewer first-year students reported seeking health care, for both physical and psychological problems, than non-first-year students. Interestingly, though, the less-ill, less-restricted first-year students reported believing that the overall health status of college students was "bad" more often than their non-first-year counterparts. This finding implies that although these first-year students may be healthier, they believe that this is a personal attribute and that college students, in general, are not very healthy. To combat this issue, college health educators should take steps to reinforce to first-year students that living healthily leads to living more healthfully in later years. As Sparling and Snow (2002) and Taylor (1999) reported, "college-appropriate" behavior patterns become predictors of overall health in adulthood. 
The results of this questionnaire provide an important snapshot of the physical health, psychological health, current lifestyles, college life stressors, and health behaviors between first-year and non-first-year college students who attended a historically Black institution in North Carolina. Moreover, these findings contribute to the identification of subgroups of students who are at particular risk for certain types of health issues that can be addressed by university officials and health and wellness personnel by implementing appropriate interventions that are tailor-made for such groups. Future research should look at how well the self-reported health behaviors of African American and other groups are meeting the health objectives for the nation outlined in the Healthy People 2010 publication. University officials and administrators along with health prevention specialists could help in addressing health issues among African American first-year and non-first-year college students by meeting national health goals and eliminating the health status disparities by implementing effective programs.

\section{Limitations}

While the findings of this study provide compelling information regarding the physical and psychological health behaviors among a mostly African American student population, limitations exist. First, a sample comprised of approximately two-thirds female students limits the generalizability of the findings to both genders. Clearly, further research with an equal male/female ratio is warranted. Next, the cross-sectional design of this study limits conclusions that can be drawn. In future investigations, the use of a longitudinal design, beginning in the freshman year and ending in the senior year of college, may enable researchers to specifically examine increasing and/or decreasing health behaviors among first-year college students.

\section{References}

Austin, A. W., Oseguera, L., Sax, L. J., \& Korn, W. S. (2002). The American freshman: Thirty-five year trends. Los Angeles: Higher Education Research Institute of the University of California, Los Angeles.

Ford, D. S., \& Goode, C. R. (1994). African American college students' health behaviors and perceptions of related health issues. Journal of American College Health, 42(5), 206-210.

Grace, T. W. (1997). Health problems of college students. Journal of American College Health, 45(6), 243-250.

Hicks, T., \& Miller, E. (in press). Life Styles, Student Life Stressors, and Health Status among Female College Students. Journal of College Admission.

Lau, R. R., Quadrel, M. J., \& Hartman, K. (1990). Development and change of young adults' preventive health beliefs and behavior: Influence from parents and peers. Journal of Health and Social Behavior, 31(3), 240-59. 
Lewis, C., Raczynski, J., Heath, G., Levinson, R., Hilyer, J., \& Cutter, G. (1993). Promoting physical activity in low-income African American communities: The PARR project. Ethnicity and Disease, 3, 101-118.

McCormack, A. S. (1996). Drinking in stressful situations: College men under pressure. College Student Journal, 30(1), 65-77.

Morgan, S. (1997). Cheap drinks, heavy costs: Students and alcohol. Youth and Policy, $56,42-54$.

Obot, I. S. (1996). Problem drinking, chronic disease, and recent life events. In H. W. Neighbors \& J. S. Jackson (Eds.), Mental health in Black America (pp. 45-61). Thousand Oaks, CA: Sage.

O'Malley, P. M., \& Wagenaar, A. C. (1991). Effects of minimum drinking age laws on alcohol use, related behaviors, and traffic crash involvement among American youth: 1976-1987. Journal of Studies on Alcohol, 52(2), 487-491.

Naquin, M. R., \& Gilbert, G. (1996). College students' smoking behavior, perceived stress, and coping styles. Journal of Drug Education, 26(4), 367-76.

Powe, B., \& Finnie, R. (2005, November). Smoking behavior among African American college students: Do attitudes and beliefs matter? Paper accepted for presentation at the 133rd annual meeting of the American Public Health Association, New Orleans, LA.

Sparling, P. B., \& T. K. Snow. (2002). Physical activity patterns in recent college alumni. Research Quarterly of Exercise and Sport, 73, 200-205.

Taylor, S. (1999). Health psychology (4th ed.). Boston: McGraw-Hill.

U.S. Department of Health and Human Services [USDHHS]. (2000). Healthy people 2010 (2nd ed.). Washington, DC: U.S. Government Printing Office.

U.S. Department of Health and Human Services [USDHHS]. (1999). National household survey on drug abuse. Population estimates. Rockville, MD: Public Health Service.

Vaez, M., \& Laflamme, L. (2003). Health behaviors, self-rated health, and quality of life: A study among first-year Swedish University students, Journal of American College Health, 51(4), 156-162. 